\title{
9 Gender analysis of policy-making in construction and transportation
}

\author{
Denial and disruption in the \\ Canadian green economy
}

\author{
Bipasha Baruah and Sandra \\ Biskupski-Mujanovic
}

\section{Introduction}

Countries around the world are figuring out ways to make their economies less carbon-intensive by creating new green jobs, developing less-polluting technologies and by retrofitting existing sectors such as manufacturing, construction, transportation, energy production, water and waste management (ILO, 2011). A gender-focused analysis of such green growth and development strategies reveals two major blind spots. First, women are known to have weaker access to new technologies almost everywhere in the world (Rosser, 2005; Hafkin and Huyer, 2006) so there are likely to be unequal access issues inherent in the transition to low-carbon economies. Second, it is well-established that women are already very poorly represented globally in some of the sectors that are deemed critical to the green economy. For example, women account for $9 \%$ of the global workforce in construction, $12 \%$ in engineering and $24 \%$ in manufacturing (UN Women, 2012). In the absence of appropriately targeted training, education, apprenticeships, employment placement, financial tools and supportive social policies, transitioning to a green economy may exacerbate existing gender inequities and reproduce existing norms and path-dependent knowledge in governmental strategies in the green economy.

In this chapter, we present findings from our synthesis of existing scientific and practitioner literature on promising programmes and policies for promoting employment equity in two sectors, construction and transportation, that are deemed critical for the Canadian green economy and in which women are currently severely underrepresented. In Canada, women currently comprise only $23 \%$ of those employed in transportation and $12 \%$ in construction (Statistics Canada, 2019). This could indicate a lack of commitment to equality in the green economy sector by state authorities and their policy-makers.

We choose to focus on employment in construction and transportation ${ }^{1}$ in this chapter because these sectors tend to produce well-paid stable jobs, but they are extremely male-dominated in Canada and in other Organisation for Economic Co-operation and Development (OECD) countries. We analyse employment in these two sectors while fully cognizant that in addition to increasing women's participation in male-dominated occupations that are well-compensated, we

DOI: $10.4324 / 9781003052821-9$ 


\section{Baruah and Biskupski-Mujanovic}

should be very concerned about how undervalued and underpaid women are in sectors like early childhood education, primary education, social work and health and library services that are already green. The care industry, for example, is $30 \%$ less polluting (in terms of GHG emissions) than the construction industry and the education industry is $62 \%$ less polluting than the construction industry (Women's Budget Group, 2020). As Hirshman (2008) notes:

Maybe it would be a better world if more women became engineers and construction workers, but programs encouraging women to pursue engineering have existed for decades without having much success. At the moment, teachers and childcare workers still need to support themselves. Many are their families' sole support.

Improving the status, wages and working conditions for people working in feminised green sectors is as important, if not more, as increasing women's participation in well-compensated male-dominated occupations (Baruah, 2017).

The remainder of this chapter includes the methodology and findings of our research. We provide an overview of the major barriers and opportunities that women encounter in seeking, retaining and advancing within employment in the construction and transportation sectors in Canada. This is followed by an overview of the blind spots and oversights about employment equity in Canada's green transition, and a description of promising practices and policies being pursued in the Canadian context to improve women's participation in construction and transportation. We conclude with a summary of the trends we observed in employment in these sectors in Canada and a reflection on the policies, practices and social awareness necessary to close the gender gaps.

This chapter is not intended as a comprehensive survey of women's employment or gender equality in the green economy in Canada. We were unable to undertake an intersectional analysis of gender along cross-cutting identities such as class, ethnicity and sexuality because the empirical data does not currently exist to enable such an assessment. Thus, when we refer to gender equity in this paper, we are limited to discussing those who identify biologically and socially as either women or men. In fact, the need to collect more gender-informed and gender-diverse data to inform evidence-based policy-making is one of the clearest findings from this study and those of others who have attempted to study the green transition in Canada (see, for example, Lieu Et al., 2020; MacArthur Et al., 2020). We hope that the issues identified by our research will provide the grounding and detail against which other related issues and research, perhaps using very different methodologies as well as broader conceptualisations of gender equality (including those of gender-diverse LGBTQ persons) and intersectional gender analysis, can be tested, verified and advanced.

\section{Methodology}

This knowledge synthesis is based on both scientific and practitioner literature. Peer-reviewed scholarship on women's employment in transportation and 
construction is limited. Most of the information for this study was gathered from practitioner organisations. We drew upon information from websites, annual reports, policy reviews, position papers and survey results of Canadian governmental and non-governmental organisations (NGOs), labour associations, professional networks, public policy institutes, think-tanks, financial institutions and social enterprises.

We asked ourselves several questions while reading the assembled academic literature and policy documents: Does this piece discuss employment equity? Is there mention of gender equity specifically? Does it make a reference to green or sustainable employment in transportation or construction? Although we intended to specifically collect data on women's employment in green or lowcarbon transportation and construction, we found that most of the available employment information is from the 'brown' or traditional (fossil fuel-based) forms of these sectors. We found very few specific examples of women's inclusion in employment in green transportation and construction, which supports a major finding from this study that gender equality (or employment equity, more broadly) has not been meaningfully addressed or even considered in mainstream green transition policies and practices in Canada.

\section{Findings}

We have organised findings from our knowledge synthesis under three themes. First, we identify and discuss the specific barriers and opportunities faced by women in seeking and retaining employment in these two sectors in Canada. Next, we outline blind spots and oversights in Canada's green transition that may contribute to women's underrepresentation in construction and transportation employment. Finally, we selectively present promising programmes and practices undertaken by municipalities, provincial governments, corporations and NGOs in Canada in order to reduce the gender gap in construction and transportation.

\section{Barriers and opportunities for women's employment in construction and transportation in Canada}

The challenges and opportunities women face in the transportation and construction industries are similar given that they are both non-traditional occupations for women in Canada. A non-traditional occupation (NTO) is defined as any occupation in which women or men comprise less than $25 \%$ of the workforce. Of course, it is important to emphasise that although certain occupations become male- or female-dominated over time in specific contexts due to historical and current processes of socialisation and the gendered 'logic of appropriateness' (Chappell, 2006), such categorisations are rarely static or stable. As evidenced by the parity or near-parity reached by women in fields such as medicine and law that were previously male-dominated, different sectors of employment may change over time due to shifts in societal attitudes as well as economic and political necessity. Also, some occupations within male-dominated sectors 


\section{Baruah and Biskupski-Mujanovic}

(for example, human resources, administrative and clerical services, public relations and communication, financial services) may have more than 25\% (or even $50 \%$ ) female workers, but women tend to be a minority in the most wellcompensated and stable positions, namely in trades and operations, in technical positions that require science, technology, engineering and math (STEM) training, and in management, senior leadership and boards of directors of companies. Women's underrepresentation in executive and managerial positions is, indeed, often because experience in engineering and operations is considered a prerequisite for leadership roles. In other words, the presence of women in some roles in these sectors does not necessarily translate into, the representation of their ideas, needs and priorities at the institutional level (Phillips, 1998). The global shift to low-carbon economies demands a growing array of skills - technical, business, administrative, economic and legal, among others (Baruah, 2016). Widening the talent pool in these industries is, thus, an instrumental reason for boosting the participation of women, in addition to intrinsic reasons of gender equity and fairness (IRENA, 2019).

Findings from our knowledge synthesis point to four major barriers for women in these sectors, which need to be addressed both by state and local institutions as well as other stakeholders. The barriers are a lack of adequate information and awareness about these fields of employment, gender bias and gender stereotyping, male-biased work culture and working conditions, and concerns about sexual harassment and violence against women.

\section{Barrier: Lack of adequate information and awareness}

We found that women often lack information about the opportunities and prerequisites for employment in the transport industry because careers in transportation are rarely pitched to women and girls through avenues such as recruitment sessions and career fairs (APGST, 2017). Much more needs to be done to introduce girls at an early age to the potential in these careers. Encouraging girls to study STEM fields is critical since employment in the most well-paid jobs in these two sectors (for example, installation, engineering and architecture) tend to require STEM training (Antoni Et al., 2015). Because these sectors were almost exclusively dominated by men for so long, employment information continues to travel disproportionately through male professional networks. Young men tend to find job opportunities in these fields through references from friends and relatives while women usually do not have similar social connections. Therefore, there is an urgent need to mainstream - i.e. improve equity in access to job information (ILO, 2011).

Male candidates tend to apply for jobs in these two sectors even when they meet some of the requirements, but most female candidates tend to not apply for jobs unless they meet all requirements (APGST, 2017). Women are also less likely to negotiate salaries and benefits. Women must often outperform men in male-dominated industries just to fit in and certainly to progress. The preference for male recruits in most transport jobs is very much a 'chicken-and-egg' problem 
- women often lack the necessary educational qualifications for many jobs in the transport sector, but these jobs have usually not been designed with women in mind and are, therefore, not particularly attractive (Turnbull, 2013). Thus, when it comes to selection, (male) managers are less likely to regard women as suitable candidates. Women appear to encounter both 'sticky floors and glass ceilings' in transportation (Turnbull, 2013). Careers may never get off the ground because of persistent and confining stereotypes of feminised roles. And the absence of role models and gender-balanced initiatives make moving up the ranks more challenging for women than men.

\section{Barrier: Gender bias and gender stereotyping}

Since transportation is presently such a gender-unbalanced industry, Turnbull (2013) emphasises that it is neither attractive nor welcoming to women. For this to change, the masculinist culture of the industry must be dismantled and career opportunities within the transportation industry must be publicised more directly to women. Women who do work in the transportation industry are routinely underestimated or discounted because of gender-based stereotypes. Of course, women are keenly aware of this and will often forgo applying for certain types of jobs, for example those involving fieldwork, because they know gender stereotypes will work against them. This explains, at least partially, why more women in these industries end up in administrative and clerical jobs rather than technical ones (APGST, 2017). Turnbull (2013) emphasises that social attitudes play a large part in discouraging women from pursuing careers in these fields when he writes:

the fact that sex discrimination has not disappeared from the world of work may be due, in part, to a lack of political commitment and - in some contexts - legal laxity, but the underlying cause remains embedded in social attitudes.

Thus, women in construction are either ridiculed as masculine or they are caught between expected roles and stereotypes - such as being treated as sexual objects or labelled as lesbian for choosing a more masculine field to work in (Moir Et al., 2011). Clearly, this issue highlights much broader gender inequities and problematic social attitudes based on misunderstandings and misperceptions about gender.

The transportation industry is frequently referred to in the literature as having a work culture and environment that include risks of sexual harassment and isolation. Turnbull (2013) traces the primary causes of women's low participation in the transportation sector to working conditions and argues that working time, shift work (24/7) and location of employment (i.e. at sea, driving long distances from home) are often unappealing to women (especially those with childcare or eldercare responsibilities) and the transportation sector may not only be unwelcoming, but hostile towards women. However, it is important to remember that although such factors may, to some extent, explain women's underrepresentation 
in transportation or construction employment, many women may already work in less-than-optimal environments for much less pay than they would make in the construction or transportation industry. Given the option, some women would probably prefer to work in construction or transportation simply because of the potential to earn higher wages. Because of persistent and entrenched male-biased norms in these industries, even women who are able and willing to work may not be given the option to choose between difficult or dangerous working conditions with low pay and similar conditions with higher pay (McKee, 2014; Carpenter Et al., 2017). Instead, women are assumed not to want to work in such jobs and tracked into feminised occupations in administrative and support services within these sectors. The fact that women's careers can be adversely affected by 'benevolent sexism' has also been documented in other sectors of employment (Dizik, 2016).

\section{Barrier: Male-biased work culture and working conditions}

It is impossible to neatly demarcate the barriers and opportunities women face in entering the construction and transportation sectors, from those that influence their decision to leave or remain. Turnbull (2013) analysed the barriers women face in the transportation industry using the career-cycle model. He identified issues women faced at every stage of career: attraction, selection, retention, interruption, re-entry and realisation. Attraction to the transport sector comes from exposure at school, home and community which he argues is 'heavily influenced by the HR policies of transport organisations (e.g. corporate image, commitment to equal opportunities) and societal values (e.g. prevailing views on what constitutes "men's work" and "women's work"'. Most departures (resignations and dismissals) in the transportation industry appear to occur within the first five years of employment. Therefore, women's initial experiences - how they are welcomed and treated, and whether they are supported and promoted - are critical.

Women in these sectors tend to leave work more frequently after maternity leave than at any other point in their careers (Baruah, 2018). Success in the retention of female employees, especially in the aftermath of interruptions for childbearing or other caring work, appears to be dependent both on the support of the organisation and the support of co-workers. Attitudes of male co-workers were deemed particularly important in retaining women after career interruptions. While studying the transportation sector, Peter Turnbull distinguished between gender-specific barriers, such as stereotypes about men's and women's work, and gender-intensified barriers, such as the absence of working arrangements to accommodate childcare and other reproductive responsibilities. Gender-specific barriers tend to interact with gender-intensified barriers in influencing women's decisions to leave these sectors. An example that was presented frequently in the literature was the double standard women faced when they returned to work after parental leave. While men who took parental leave were welcomed back to work and often valourised for their commitment to parenting, women were more likely to find their commitment to work being implicitly or explicitly questioned, 
to be taken less seriously by colleagues and superiors and to feel that they were no longer competitive or competent in their positions (Baruah, 2018). Such findings shed light upon why ostensibly gender-neutral institutions have differential effects upon women and men. Feminist institutionalist approaches are used to answer questions about power inequalities, mechanisms of continuity, and the gendered limits of change (see e.g. the introduction to this volume). Feminist institutionalist literature emphasises that it is crucial to identify how informal norms and behaviours interact with formal institutions and policies in order to understand wider processes of continuity and change as well as variable outcomes for women and men (Krook and Mackay, 2010).

Arcand (2016) arrives at similar findings about women's experiences in the construction industry:

Women tend to enter the industry with fewer skills than their male counterparts, not having access to informal networks commonly used to find work, being let go once diversity quotas have been met, and encountering hostile work environments and sexual harassment on the job.

The fact that informal networking is still the norm rather than the exception for seeking apprenticeships and employment in the trades is identified repeatedly as a barrier to women's entry into and advancement in these fields (National Women's Law Centre, 2014). Thus, female construction workers refer (not facetiously) to their inability to access FBI (friends, brothers and in-laws) networks as a major impediment in gaining full-time employment in the trades (National Women's Law Centre, 2014). Gender-disaggregated data on the number of new registrations in apprenticeship programmes in Canada paint a stark picture. In 2015, for example, there were just 66 women enrolled as machinists, compared to $1,545 \mathrm{men}$. There were 54 women registered as sheet metal workers, compared to 1,476 men (Smith, 2017). The need for policies aimed at enabling fair and equitable access to apprenticeships is urgent and critical for promoting equity in these sectors.

\section{Barrier: Concerns about sexual harassment and violence against women}

Violence against women transport workers is frequently reported as a factor limiting women's ability or willingness to seek and keep transportation jobs (Turnbull, 2013). Moir Et al. (2011) emphasise the same about the construction industry. They suggest that because construction work is carried out autonomously or with minimal supervision and often in dark corners, trenches, and small or secluded spaces, there are concerns about safety, especially for female workers. The Health and Safety of Women in Construction (HASWIC) Workgroup reported that $88 \%$ of female construction workers surveyed had experienced sexual harassment at work (Moir Et al., 2011). The immediate safety risks for women can certainly be mitigated by certain actions and practices (better lighting and working in 
pairs, for example) but eliminating violence against women will require much deeper and more proactive engagement with the social structures and power relations that sustain and reproduce it. We found very little engagement in the literature on construction and transportation with the structural causes of violence against women.

As more jobs are created in these sectors due to the transition to low-carbon economies, equitable representation of women in transportation and construction is becoming even more important. In Canada, women's employment in the transportation industry ranges between $22 \%$ and $25 \%$ while women's employment in the overall labour force is $48 \%$ (APGST, 2017). The lowest employment rate for women is in rail and truck transportation, 13\% and 14\% respectively, while the postal service and air transportation have the highest representation of women, at 50\% and 39\%, respectively. Canada will create 200,000 new jobs in the construction industry over the next decade but women only account for $4 \%$ of new registrants in the construction trades (Status of Women Canada, 2017). Retrofitting and upgrading residential buildings will make up a third of projected global green jobs (Sustainlabour, 2009). Additionally, the transportation sector is expected to contribute substantially to green growth through fuel-efficient vehicles, new infrastructure and public transport.

\section{Opportunities}

We found wages in construction and transportation to be more gender-equitable than wages in other sectors of the economy. For example, women in construction earn 98 cents for every dollar earned by a man compared to earning just 75 cents for every dollar earned by a man in the personal care and services field (Arcand, 2016). The gender wage gap can be narrowed further by encouraging women's participation in construction and other non-traditional occupations. Hegewisch and O'Farrell (2015) argue that women may be especially valuable in green construction because of their higher interest in environmental issues compared to men. They write that in the US and Canada women represent more than one in five environmental engineers, but only one in eight civil engineers. The same study reports that people who are already employed in the traditional construction industry can access training in green construction skills quite easily. Since women are a minority in the traditional construction sector, their ability to access green construction training is significantly weaker than their male counterparts. Most women who are in the traditional construction sector in North America indicated that green training and work is part of their construction trade and not a separate route into the trades. This highlights the need to influence equity practices in the traditional construction sector and not just in green construction. Thus, our findings from Canada echo those of Clarke and Sahin-Dikmen (in this volume) from the European Union, who emphasise that there is scant evidence to suggest that gender has even entered mainstream green transition approaches in construction.

In a report about good practices for the construction sector, Peters and Katalytik (2011) emphasise that companies with more women on their boards 
fare better than their rivals, with a $42 \%$ higher return on sales, $66 \%$ higher return on invested capital and $53 \%$ higher return on equity. This data should encourage employers not just to recruit women for entry-level positions but also to make the effort to retain and promote them to leadership positions. Better gender balance in male-dominated professions has been demonstrated to contribute to the improvement of working conditions for both men and women, with positive effects on wellbeing, work culture and productivity. A respectful workplace is a workers' issue, not just a women's issue (Kong, 2020).

There is tremendous potential in Canada, and globally, to create and optimise livelihoods for women in transportation and construction. However, women can gain optimal traction from employment in these fields only within the context of wider socially progressive pro-women policies, as well as more transformative shifts in societal attitudes about gender roles. This is as true for developing countries and emerging economies as it is for industrialised nations (Baruah, 2016). The green transition in these two sectors should benefit both women and men, but policy-makers must be proactive about enabling women to establish a stronger equity stake to compensate for historical and contemporary economic injustices and unequal outcomes. This will require more concrete and proactive actions and policies. As evidenced by our findings from Canada, simply creating opportunities for training and employment in new fields and suggesting that women are not unwelcome in them is not enough (Baruah and Biskupski-Mujanovic, 2018).

\section{Blind spots and oversights about employment equity in the green transition in Canada}

Some of the challenges faced by women in transportation and construction may be exacerbated by blind spots and oversights in the green transition in Canada. Planning and implementing measures for employment equity in the green economy is critical for Canada. Most green initiatives in Canada have been driven by the private sector, municipalities and provincial governments. The federal government has, at least until very recently, not played an active role in framing and implementing effective policies to enable the transition to a low-carbon economy. Despite growing evidence of the potential for the green economy to generate a larger volume of employment than the 'brown' (fossil fuel-based) economy, even organisations committed to advocating for equity and social justice in environmental sustainability in Canada have never specifically mentioned or addressed gender inequity. As an example, the One Million Climate Jobs Campaign - an alliance of labour, social movements and other civil society organisations in Canada - is mobilising for practical solutions to the threat of climate change. Although the campaign claims to place the interests of workers and the poor at the forefront of strategies to combat climate change and demands that governments work to create 'one million climate jobs', it makes no mention whatsoever of the importance of addressing gender inequity. Reports that do highlight opportunities to employ underrepresented groups, including women, in the green economy stop short of calling for specific policies and concrete actions 
required to ensure gender equity (see, for example, Blue Green Canada, 2012; Katz, 2012). We found more evidence in such reports for calls for equity measures to improve the representation of other underrepresented groups in Canada, namely, workers with disabilities and Indigenous peoples, than for improved representation of women.

It is difficult to identify straightforward explanations for why gender inequality has not permeated the public or policy consciousness in the transition to a green economy in Canada. The conversation about gender issues in the green economy has been much more prominent in the context of developing countries (see, for example, ILO, 2011; IUCN, 2011; UN Women, 2012), where the gender gaps in education and employment may be more prominent and visible. The lack of attention paid to gender equity in the green economy in Canada and other industrialised countries may be a result of the assumption that because women and girls increasingly enjoy parity with men and boys in educational opportunities and employment, they cannot possibly be underrepresented or marginalised in some sectors. The fact that women represent more than $50 \%$ of university students and almost half $-48 \%$ - of the labour force in Canada (Statistics Canada, 2019) may have obscured their extreme underrepresentation and marginalisation in traditionally masculinist trades and occupations. Several authors have also noted that popular mythologies about Canada being a 'post-gender' and 'post-racial' society often end up encouraging complacency among policy-makers and deflecting attention away from persistent social, economic, and political inequalities between Canadians based on gender and race (Subramaniam, 2020). Recent developments such as the COVID-19 pandemic in 2020 - which is being described as a 'she-cession' (Trichur, 2020) because of the disproportionate job losses in feminised sectors such as retail and hospitality services compared to male-dominated industries such as construction, transportation, and manufacturing (that are more easily adaptable for social distancing requirements) - may lead to a reckoning that compels more attention in the future to gender inequity in the green economy.

Some of the most well-paid future green jobs in Canada will be in occupations in which women are currently underrepresented, such as engineering and the skilled trades (Katz, 2012). A Statistics Canada study found that in 2007 women only accounted for $1-2 \%$ of completions in apprenticeship training in major trade groups (McMullen Et al., 2010). In 2018, women made up only $18 \%$ of newly licensed engineering graduates in Canada (Engineers Canada, 2020). According to a 2016 report by the Canadian Apprenticeship Forum (CAF-FCA), in 2012 women accounted for only $14.2 \%$ of all registrations in the trades. However, most women in the trades are employed in the feminised service sectors, including some green trades (as bakers, hairstylists, nail technicians, and pet groomers, for example), not in the male-dominated manufacturing and construction trades - especially those governed by the Red Seal Interprovincial Standards Program. Red Seal tradespeople have been trained to the same standards across the country, allowing them to move more easily between provinces. In fact, women's representation in many trades - including as automotive service technicians, electricians, and carpenters - is at less than $5 \%$. The numbers are even smaller when it comes 
to women of colour. The same CAF-FCA report says, 'nearly half of Red Seal trades have no visible minority women, and the other half only between one and 12\%' (quoted in Kong, 2020). Since tradespeople have been known to transition from jobs in the 'brown' economy (which is heavily male-dominated) to the 'green' (Baruah and Gaudet, 2016), it seems inevitable that women will also be underrepresented in green jobs unless gender equity in employment is planned and implemented proactively. Recent media reports confirm this trend, indicating that $25 \%$ of students studying to be wind turbine technicians in Alberta, Canada, were once oil and gas workers (Canadian Press, 2017), and that laid-off oil and gas workers in Alberta are using their unemployment benefits to retrain and find employment in the clean energy sector (Bickis, 2016).

The conversation about gender equity or social justice (more broadly) in Canada's green economy is at best incipient and tokenistic. Raising awareness is, therefore, urgent and critical. In 2016, the OECD reported that although Canada performs better than the OECD average for the gender employment gap $(6.1 \%$ compared to $11.7 \%$ ), the gender wage gap is above the OECD average (19\% compared to $15.5 \%$ overall). Not only does Canada have a large gender wage gap, but women are severely underrepresented in all green growth sectors (Thirgood Et al., 2017). The types of policies and programmes put in place by governments and corporations will promote or impede opportunities for women. Although employment in the green economy in Canada is a growing topic of research and policy engagement, the need to promote gender equity in green jobs is rarely a topic of conversation. For example, the One Million Climate Jobs campaign proposes a $5 \%$ investment of the annual federal budget in renewable energy, energy efficiency and public transportation in order to create one million new jobs while reducing greenhouse gas emissions by 25-35\%. Although this campaign discusses the types of jobs that will be created through such an effort quite extensively, there is no explicit or even subtle mention of employment equity.

A 2015 report prepared by the Steering Committee of the Green Economy Network in Canada identifies priority areas to stimulate the transition to a green economy, including a renewable energy development strategy, improved energy efficiency of homes and buildings, and expanded public transit. The report emphasises that millions of new decent jobs would be created by transitioning to a green economy. In order to ensure social equity, this report suggests creating a transition fund to assist workers displaced by the phasing out of fossil fuel production, to promote affirmative action for members of marginalised communities, and to enable consultation with Indigenous peoples. Among the suggested equity measures, there is no mention of gender and no consideration of the underrepresentation of women in the industries that will help Canada reduce greenhouse gas emissions.

\section{Promising policies and programmes in Canada}

In 2019, the Canadian Apprenticeship Forum (CAF-FCA) published a labour market report that showed that from 2019 to 2023 an estimated 67,000 new 
certified workers will be required to sustain workforce certification levels across the ten largest Red Seal trades in Canada. Keeping pace with the demand for skills and workforce certification will require attracting 167,739 new apprentices over the next five years (Kong, 2020). This will not be possible or sustainable without concrete efforts to bring in populations that are currently severely underrepresented: namely women, Indigenous peoples, and people with disabilities.

Despite evidence of severe skill shortages in construction and transportation, and adequate knowledge about the barriers to entry and retention for women (described in a previous section of this chapter), we did not find much evidence to suggest that concerted effort was being made in Canada, especially at the federal level, to design policies or to establish targets to attract and recruit more women to the trades. As with the invisibility of gender issues during the green transition, it appears that the tremendous gains made by Canadian women in post-secondary education and the labour market in recent decades may have obscured the fact that they remain severely underrepresented in the trades. There is some evidence of trade schools and educational institutions trying to alleviate financial barriers women may face. Conestoga College's School of Engineering and Technology, for example, provides free training for women in the skilled trades. These are called pre-apprenticeship programmes since they provide basic training that prepares women for entering a trade and securing an apprenticeship (Kong, 2020).

The Centre for Skills Development and Training, which has five locations in the province of Ontario offers resources for women looking to enter the residential construction industry with its Women in Skilled Trades (WIST) programme. Women learn about tools, energy star building practices, the building code, and marketing and communications. Pre-apprenticeship programmes that provide women with flexible childcare, financial aid, and wraparound supports, from counselling to subsidies for equipment and boots, also help. Something as simple as providing women with safety clothing can make a difference since there are safety hazards for women working in men's clothing.

There is also some evidence of efforts aimed at addressing other challenges women face in transportation and construction. In most instances, the efforts are driven by provincial and municipal governments, non-profit organisations, and private sector companies. For example, violence against women has been identified as a barrier for women's equitable access to and employment in public transit. The city of Toronto has initiated the Metropolitan Toronto Action Committee on Violence against Women and Children (METRAC), a collaborative relationship formed by community-based women's organisations, the Toronto Transit Commission, and the Toronto Police Department, to conduct safety audits of the city's transport system. The Toronto Transit Commission (TTC) has a mandate to staff its workforce with 'employees as diverse as the riders it serves' (McIntyre, 2015). The City of Toronto's benchmark for women's employment in transportation in $48.7 \%$. While women account for $57 \%$ of ridership, they only accounted for $15 \%$ of its workforce in 2014 . To respond to this unimpressive number, the TTC has introduced the Diversity and Inclusion Lens and Toolkit to guide 'managers and employees to consider the potential impacts of projects, actions 
and initiatives on diverse employees and customers' (TTC, 2017). The toolkit includes a guide to inclusive language on disability, race, ethnicity, Indigenous peoples, gender, gender identity, and gender expression, sexual orientation, and LGBTQ+. One guideline from the toolkit states: 'Avoid making assumptions based on stereotypes/unconscious biases, such as assuming clerks are female, or assuming mechanics are male'.

Some provincial governments in Canada have also made efforts to improve employment equity in construction and transportation. For example, the government of Alberta began an outreach initiative called 'Women in Non-traditional Occupations: Stories to Inspire' to make role models visible for women. This initiative reaches out to women who are interested in, but wary of, careers in non-traditional occupations by sharing stories of how successful women addressed issues of feminised stereotypes, attitudes of men, physical requirements, and assumed incompetence for non-traditional work (Alberta Human Services, 2013). Also, in the same province, the Alberta Council of Turnaround Industry Maintenance Stakeholders (ACTIMS), which includes oil sands owners, heavy industrial maintenance contractors and labour providers run the Women in Trades Awards/ Bursaries Program to recognise female members of the Canadian Building Trades and to create awareness about opportunities for women in the skilled trades. Each year, this organisation provides three recipients with $\$ 1,500$ (one for any woman Journeyman, ${ }^{2}$ and two for apprentices). Although the intent of the project is laudable, ACTIMS should take note of the power of language in their quest to combat women's underrepresentation in the field; 'woman Journeyman' is not as inclusive as 'journeywoman' or 'journeyperson'.

In British Columbia, Cohen and Braid (2000) conducted research on the Vancouver Island Highway Project (VIHP) and its efforts to integrate women and Indigenous communities as part of its commitment to equity initiatives. They found that at its peak production periods, the equity hires constituted more than $20 \%$ of the workforce, ten times higher than usual. Women's participation in the project reached $6.5 \%$ and Indigenous workers reached $7.5 \%$ (9\% and $11 \%$ at peak times, respectively). Further, $93 \%$ of the workforce consisted of local hires. The equity provisions in this programme had support at the highest levels, including from the Premier of British Columbia, and they were continually monitored and supported by women's groups and Indigenous peoples' organisations on Vancouver Island. The local community strongly supported the initiative since local hires dominated the workforce of the project and all labour on the VIHP was unionised. Initially, few members of the targeted equity groups applied but recruitment practices were changed as a result. Active recruitment on Indigenous reserves and in women's centres was a remedy to this barrier and the interview process was even adjusted to consider volunteer or other non-paid labour as work experience. Cohen and Baird note that the workplace culture on the VIHP project changed over time. Female workers were frequently reported to have better attitudes and work ethic. The project also had an Employment Equity Coordinator, whose role was to advocate for employment equity, and an Equity Integration Committee, which ensured constant monitoring of the equity initiative. 
Another example of a Canadian provincial programme that encourages women's employment in transportation is in Newfoundland and Labrador, where the Office to Advance Women Apprentices offers a wage subsidy of up to $75 \%$ for two contracts as an incentive for employers to hire female apprentices. However, we were unable to find any evidence to understand what happens to these women's careers once the subsidy runs out. Speaking more broadly about findings from this research project, we found very little information about the long-term sustainability or outcomes of gender equity initiatives in construction and transportation. Future research should address the long-term impact of these programmes, identifying where there is room for improvement, providing detailed documentation of what has worked well and what has not, and evaluating the potential to scale up successful initiatives at the provincial or national level.

The non-profit sector in Canada has also driven some equity initiatives, sometimes in partnership with provincial and municipal governments. For example, Building Up and BUILD Inc. are two non-profit social enterprises that offer employment and training in the construction trade to those with barriers to employment (i.e. visible minorities, those with criminal records, high school dropouts). Building $\mathrm{Up}_{\mathrm{p}}$ is based in Toronto. It provides energy and water retrofits in affordable housing while employing those living in poverty, often from within the public housing units they live in. Building Up calls itself a 'social contractor' and specifically trains and employs those with the most barriers to employment. They offer 16-week paid apprenticeships and $90 \%$ of their graduates go on to full-time employment in the skilled trades. BUILD Inc. partners with Manitoba Hydro (the provincial utility company) to improve insulation in low-income housing to reduce carbon emissions and to lower utility bills. They offer a six-month paid training programme for those who 'would often be deemed unemployable'. BUILD Inc. also offers life skills, vocational training, and remedial education on topics such as math and money management. Although there is no explicit focus on gender, there is a very clear mandate to work with those who have the most significant barriers to employment, often including women and Indigenous workers.

The record of trade unions and industry associations in Canada has been somewhat erratic in promoting employment equity. For example, Canada's Building Trades Union (CBTU) released a report in July 2017, the first original study on the impacts of Canada's transition to low-carbon development upon the construction industry. The report identifies new employment opportunities that will emerge if Canada meets its commitment to the 2015 Paris Agreement. The report contained no sex-disaggregated data and no mention of women, gender, or equity. It proposes that moving to an electrical supply grid would result in over 1.75 million jobs but fails to consider who might get these jobs and who might be left out. Despite such glaring oversights, CBTU does run Women in the Building Trades, an initiative that promotes creating 'the space for conversation on how to engage women' in construction. The initiative focuses on outreach activities including tradeshows, career fairs, mentorship events and networking functions. 
'Build Together', a Canadian national programme focused on the recruitment and retention of workers from underrepresented portions of the population, has compiled a list of suggestions for what a union or employer can do in order to attract women to the construction sector. Their recommendations to unions and other representative organisations for building a more inclusive and diverse construction sector include training for diversity and respectful workplaces, putting pressure on industry leaders to promote inclusivity, mentorship programmes, networking and conferences to build community and ease isolation, ensuring proper safety equipment and gear for women, flexible hours to navigate childcare and family needs, and starting a women's committee. Unions and other organisations that represent workers do have the opportunity and responsibility to play an important role in promoting women's employment in transportation and construction. With $80 \%$ of female apprentices participating in union-sponsored programmes, union apprenticeship programmes have had greater success at recruiting women and ensuring completion of training than non-unionised programmes (Arcand, 2016). However, as several researchers writing about unions have pointed out (see, for example, Baker and Robeson, 1981) unions are often themselves masculinist organisations that have historically ignored women and other socially marginalised groups. Depending on the setting, unions may be in as much need of institutional reform as other organisations.

\section{Conclusion}

In Canada, women make up only $23 \%$ and $12 \%$, respectively, of those employed in transportation and construction. Concerns about climate change and fossil fuel insecurity have ensured that there is significant interest in the technologies and financing for transitioning to a low-carbon economy, but far too little attention is being paid in Canada to the employment equity implications of such a transition. Although we intended to specifically collect data on women's employment in green or low-carbon transportation and construction, we found that most of the available data and information on employment is from the 'brown' or traditional (fossil fuel-based) forms of these sectors. We found very few specific examples of women's inclusion in employment in green transportation and construction, which supports a major finding from this study that gender equality (or employment equity, more broadly) has not been meaningfully addressed or even considered in mainstream green transition policies and practices in Canada.

In the absence of appropriately targeted training, education, apprenticeships, employment placement, financial tools, and supportive social policies, transitioning to a green economy may exacerbate existing gender inequities and social hierarchies. This chapter synthesised and assembled existing scientific and practitioner literature on promising programmes and policies for promoting and optimising women's employment in two sectors that are critical for the Canadian green economy and in which women are currently severely underrepresented, namely, construction and transportation. Our findings reveal that there are 
currently significant gender inequities in employment trends in these sectors in Canada.

Our findings suggest that people who are already employed in the traditional (fossil fuel-based) versions of these industries can access green skills and training more easily than people who have never worked in these sectors. Since women are severely underrepresented in the traditional construction and transport sectors, their ability to access green skills and training is significantly weaker than men. Further, our findings confirm that although green training is part of the existing trades in these sectors, it does not presently constitute a separate route into them. This highlights the need to influence and implement equity practices in the traditional construction and transport sectors in order to ensure equitable representation of women in the low-carbon iterations of these industries.

Most existing equity initiatives in Canada in these two sectors have been driven by the private sector, municipalities, and provincial governments. The federal government has, at least until very recently, not played an active role in framing and implementing effective policies to enable the transition to a green economy. Canada has been hindered in this regard by a political structure that divides responsibility for policies related to climate and energy between the federal government and the provinces. This has led to a patchwork of policies at the provincial level exacerbated by an absence of federal leadership on the issue. The current Liberal federal government has made more explicit commitments to a green economy and climate change mitigation. But there has been virtually no effort from the federal government to initiate policies on employment equity in the transition to a green economy. The federal government must play a stronger leadership role in implementing employment equity policies in order to motivate and optimise the efforts of other actors in the green economy.

Our findings highlight the need for a collective and cohesive national strategy that has measurable outcomes and actual numerical targets monitoring to improve women's access to, and retention, in the growing green economy. Since women are already underrepresented and marginalised in key sectors of the green economy, growth in green industries may further exclude women if proactive measures are not adopted. McFarland (2013) argues that given women's current pattern of participation in jobs and training in the trades, almost none of the green jobs we expect to be created would go to women. She stresses the dire need for equity programmes and quotas that are monitored and enforced. In addition to federal and provincial leadership on policy issues, Canada needs all stakeholders, including federal, provincial, and municipal governments, civil society organisations, corporations, labour associations, public policy institutes, and think-tanks to work together to ensure that women are not further marginalised as more green jobs are created in transportation and construction.

While emphasising the need for effective policy interventions to ensure employment equity in the transition to low-carbon economies, our findings suggest that even well-planned and well-designed policy interventions may not adequately subvert the broader social structures that create the inequities in the first 
place. Most policies designed to address women's underrepresentation in these fields tend to be reactive responses that do not engage adequately with structural social, economic, and political inequality. Improving the lighting in construction sites in order to prevent sexual assaults against women and requiring women to work in pairs instead of alone are classic examples of reactive policies that have already been adopted by some employers but that may, ironically, end up reinforcing and institutionalising gendered social hierarchies rather than challenging them (Connell, 1990; Krook and MacKay, 2010). We found that the most common response to women's underrepresentation in these fields has been to 'add women and stir', simply adding women to industries with unchanged masculinist values and work cultures (Harding, 1995). Policy responses also often reinforce affirmative gender essentialisms. Women tend to be valourised in essentialist ways that reinforce existing social hierarchies. For example, assumptions that women are gentler with machinery than men and therefore maintain machinery better or that women bring specific valuable qualities and skills (empathy, patience) to the job simply by being women reinforce social hierarchies since most women acquire these skills because of historical and current social oppression and not because they are biologically female.

Our findings suggest that although the formal realm of law and policy can and does play a significant role in optimising women's employment and retention in the labour force, legislation, and policy cannot be the sole vehicles for social change because they are not enough to alter entrenched gender roles, social hierarchies and entitlements. Consciousness-raising initiatives that raise awareness among women, as well as men, about the benefits of greater equity and women's equal entitlements to employment in all fields are as crucial as policy reforms and state or corporate actions that protect women's interests and facilitate their agency.

\section{Notes}

1 The energy sector, which is both critical for the green economy and in which women are also extremely marginalised, is not included in this chapter because we have already published extensively on this topic elsewhere (see, for example, Baruah, 2016; Baruah and Gaudet, 2016).

2 'Journeyman' is a term used in Canada to describe a skilled tradesperson who has successfully completed an official apprenticeship qualification.

\section{References}

Alberta Human Services (2013) Women in Non-Traditional Occupations: Stories to Inspire[online]. Available at: https://open.alberta.ca/publications/9780778569374. (Accessed: 13 October 2020).

Antoni, M., Janser, M. and F. Lehmer. (2015) 'The Hidden Winners of Renewable Energy Promotion: Insights into Sector-Specific Wage Differentials', Energy Policy, 86, pp. 595-613.

Arcand, C. (2016) 'Women in Construction and the Workforce Investment Act: Evidence from Boston and the Big Dig', Labor Studies Journal, 41(4), pp. 333-354. 
Asia Pacific Gateway Skills Table (2017) Women in Transportation Careers: Moving Beyond the Status Quo [online]. Available at: https:/www.westac.com/application/ files/8015/0161/4819/WIT-Report-2017-Final-Web.pdf (Accessed:13 October 2020).

Baker, M. and M., Robeson. (1981) 'Trade Union Reactions to Women Workers and Their Concerns', Canadian Journal of Sociology, 6(1), pp. 19-31.

Baruah, B. (2016) 'Renewable Inequity? Women's Employment in Clean Energy in Industrialised, Emerging and Developing Economies', Natural Resources Forum, 41(1), pp. 18-29.

Baruah, B. (2017) 'Renewable Inequity? Women's Employment in Clean Energy in Industrialised, Emerging and Developing Economies', in Cohen, M.G. (ed.), Gender and Climate Change in Rich Countries: Work, Public Policy and Action. London, UK: Routledge, pp. 70-86.

Baruah, B. (2018) 'Barriers and Opportunities for Women's Employment in Natural Resources Industries in Canada', Report presented at Natural Resources Canada, Ottawa, November 27.

Baruah, B. and C., Gaudet. (2016) 'Confronting the Gender Gap in Canada's Green Transition', Western News, September 21 [online]. Available at: https://news.we sternu.ca/2016/09/baruah-gaudet-confronting-gender-gap-canadas-green-transition/ (Accessed 13 October 2020).

Baruah, B. and S. Biskupski-Mujanovic. (2018) Identifying Promising Policies and Practices for Promoting Gender Equity in Global Green Employment [online]. Available at: https://institute.smartprosperity.ca/library/research/identifying-promising-policies-and -practices-promoting-gender-equity-global-green (Accessed 1 October 2020).

Bickis, I. (2016) 'Renewable Energy, Other Industries Draw laid-off Oil and Gas Workers', Huffington Post, 27 January[online]. Available at: http://www.huffingtonpost.ca/2016/0 1/27/oil-and-gas-career-change_n_9089360.html (Accessed 1 October 2020).

Blue Green Canada (2012) Building Ontario's Green Economy: A Road Map [online]. Available at: http://environmentaldefence.ca/report/report-building-ontarios-green-e conomy-road-map/ (Accessed 13 October 2020).

Canada's Building Trades Unions (CBTU) (2017) Jobs for Tomorrow: Canada's Building Trades and Net Zero Emissions [online]. Available at : https://adaptingcanadianwork .ca/jobs-for-tomorrow-canadas-building-trades-and-net-zero-emissions/ (Accessed 13 October 2020).

Canadian Apprenticeship Forum (CFA-FCA) (2016) Apprenticeship Analysis Women and Apprenticeship in Canada [online]. Available at: https://caf-fca.org/wp-content /uploads/2017/07/Member9_Women-and-Apprenticeship.pdf (Accessed 13 October 2020).

Canadian Press (2017) Laid Off Oil and Gas Workers Train for Alternative Energy Jobs as Wind Blows Alberta in New Direction [online]. Available at: https://www.cbc.ca/news /canada/calgary/alternative-energy-training-laid-off-oil-and-gas-1.4463217 (Accessed 1 October 2020).

Carpenter, J., Matthews, P. and A. Robbett. (2017) 'Compensating Differentials in Experimental Labor Market', Journal of Behavioral and Experimental Economics, 69, pp. 50-60.

Chappell, L. (2006) 'Comparing Political Institutions: Revealing the Gendered "Logic of Appropriateness”, Politics E⿱乛 Gender 2 (2), pp. 223-235.

Cohen, M. and K. Braid. (2000) 'Training and Equity Initiatives on the British Columbia Vancouver Island Highway Project: A Model for Large-Scale Construction Projects', Labour Studies Journal, 25 (3), pp. 70-103. 
Connell, R.W. (1990) 'The State, Gender, and Sexual Politics: Theory and Appraisal', Theory and Society, 19 (5), pp. 507-544.

Dizik, A. (2016) 'Where are All the Expat Women?', BBC Worklife [online]. Available at: https://www.bbc.com/worklife/article/20160929-where-are-all-the-expat-women (Accessed 1 October 2020).

Engineers Canada (2020) Women in Engineering [online]. Available at: https://enginee rscanada.ca/diversity/women-in-engineering/30-by-30 (Accessed 13 October 2020).

Hafkin, N. and S., Huyer. (2006) Cinderella or Cyberella? Empowering Women in the Knowledge Society. Boulder: Kumarian Press.

Harding, S. (1995) 'Just Add Women and Stir?' in United Nations Commission on Science and Technology for Development (ed.) Missing Links: Gender Equity in Science and Technology for Development. Ottawa: International Development Research Centre, pp. 295-308.

Hegewisch, A. and B., O'Farrell. (2015) Women in the Construction Trades: Earnings, Workplace Discrimination, and the Promise of Green Jobs [online]. Available at: https ://iwpr.org/wp-content/uploads/wpallimport/files/iwpr-export/publications/C428-W omen\%20in\%20Construction\%20Trades.pdf (Accessed 13 October 2020).

Hirshman, L. (2008) 'Where Are the New Jobs for Women?', New York Times, December 9 [online]. Available at: http://www.nytimes.com/2008/12/09/opinion/09hirshman.ht $\mathrm{ml}$ ?_r $=0$ (Accessed 13 October 2020).

ILO (2011) Promoting Decent Work in a Green Economy [online]. Available at: https ://www.ilo.org/employment/Whatwedo/Publications/WCMS_152065/lang--en/index. htm (Accessed on 13 October 2020).

IRENA (2019) Renewable Energy: A Gender Perspective [online]. Available at: https:// irena.org/-/media/Files/IRENA/Agency/Publication/2019/Jan/IRENA_Gender_perspe ctive_2019.pdf (Accessed 13 October 2020).

IUCN (2011) A Gender Perspective on the Green Economy [online]. Available at: https ://www.iucn.org/content/a-gender-perspective-green-economy (Accessed 13 October 2020).

Katz, J. (2012) Emerging Green Jobs in Canada: Insights for Employment Counsellors into the Changing Labour Market and its Potential for Entry-Level Employment [online]. Available at: http://www3.cec.org/islandora-gb/en/islandora/object/islandora\%3A 1193 (Accessed 13 October 2020).

Kong, S.L. (2020) 'Why We Need More Women in These Particular Careers Than Ever Before', Macleans, February 3 [online]. Available at: (https://www.macleans.ca/work/w omen-in-skilled-trades/(Accessed on April 26, 2020).

Krook, M. and F., Mackay. (eds.) (2010) Gender, Politics and Institutions: Towards a Feminist Institutionalism. London: Palgrave Macmillan.

Lieu, J., Sorman, A., Johnson, O., Virla, L. and B. Resurrección. (2020) 'Three Sides to Every Story: Gender Perspectives in Energy Transition Pathways in Canada, Kenya and Spain', Energy Research and Social Science. https://doi.org/10.1016/j.erss.2020 .101550

MacArthur, J., Hoicka, C., Castleden, C., Das, R. and J. Lieu. (2020) 'Canada's Green New Deal: Forging the Socio-Political Foundations of Climate Resilient Infrastructure?', Energy Research Ë Social Science. https://doi.org/10.1016/j.erss.2020.101442

McFarland, J. (2013) 'The Gender Impact of Green Job Creation', Paper presented at Work in a Warming World International Conference, Toronto, November 29-December 1.

McIntyre, C. (2015) 'TTC Falls Short on Gender Equality Targets', Torontoist, 23 December [online].Available at: http://torontoist.com/2015/12/ttc-falls-short-on-g ender-equity-targets/ (Accessed 13 October). 


\section{Baruah and Biskupski-Mujanovic}

McKee, L. (2014) 'Women in American Energy: De-feminizing Poverty in the Oil and Gas Industries', Journal of International Women's Studies, 15(1), pp. 167-178.

McMullen, K., Gilmore, J. and C. Le Petit. (2010) Women in Non-traditional Occupations and Fields of Study [online]. Available at: https:/www150.statcan.gc.ca/n1/pub/81-0 04-x/2010001/article/11151-eng.htm (Accessed 13 October 2020).

Moir, S., Thomson, M. and C. Kelleher. (2011) Unfinished Business: Building Equality for Women in the Construction Trades. Labor Resource Center Publication [online]. Available at: https://scholarworks.umb.edu/cgi/viewcontent.cgi?article=1004 \&context=lrc_pubs (Accessed 13 October 2020).

National Women's Law Center (2014) Women in Construction: Still Breaking Ground [online]. Available at: https://nwlc.org/wp-content/uploads/2015/08/final_nwlc_ womeninconstruction_report.pdf (Accessed 13 October 2020).

OECD (2016) Promoting Green and Inclusive Growth in Canada [online]. Available at: http://www.oecd.org/canada/promoting-green-and-inclusive-growth-in-canada.pdf (Accessed 13 October 2020).

Peters, J. and M., Katalytik. (2011) Equality and Diversity: Good Practice for the Construction Sector. Equality and Human Rights Commission [online]. Available at https://www.equalityhumanrights.com/sites/default/files/ed_report_construction_s ector.pdf (Accessed 13 October 2020).

Phillips, A. (1998) The Politics of Presence. London and New York: Oxford University Press.

Rosser, S. (2005) 'Women and Technology Through the Lens of Feminist Theories', Frontiers: A Journal of Women's Studies, 26(1), pp. 1-23.

Smith, J. (2017) 'Women Account for Just 4.5\% of Skilled Trade Workers in Canada', Canadian Press, 25 October [online]. Available at: https://globalnews.ca/news/382 3621/women-skilled-trades-manufacturing/ (Accessed 13 October 2020).

Statistics Canada (2019) Employment by Industry and Sex [online]. Available at: http: //www.statcan.gc.ca/tables-tableaux/sum-som/101/cst01/labor10a-eng.htm (Accessed 13 October 2020).

Status of Women Canada (2017) The Competitive Advantage: A Business Case for Hiring Women in the Skilled Trades and Technical Professions [online]. Available at: https://cfc-swc.gc.ca/abu-ans/wwad-cqnf/bc-cb/business-case-en.pdf (Accessed 13 October 2020).

Steering Committee of the Green Economy Network (2015) Making the Shift to a Green Economy: A Common Platform of the Green Economy Network [online]. Available at: https://canadianlabour.ca/research/issues-research-making-shift-green-economy/ (Accessed 13 October 2020).

Subramaniam, V. (2020) 'Before You Declare Canada is Not a Racist Country, Do Your Homework', National Post, June 2 [online]. Available at: https://nationalpost.com/ opinion/vanmala-subramaniam-before-you-declare-canada-is-not-a-racist-country-do -your-homework (Accessed 13 October 2020).

Sustainlabour (2009) Green Jobs and Women Workers: Employment, Equity and Equality [online]. Available at : http://www.greengrowthknowledge.org/sites/default/files/down loads/resource/Green_jobs_and_women_workers_employment_equity_equality_Sust ainlabour.pdf (Accessed 13 October 2020).

Thirgood, J., McFatridge, S., Marcano, M. and J. Van Ymeren. (2017) Decent Work in the Green Economy [online]. Available at: https://munkschool.utoronto.ca/mowatcentre/ decent-work-in-the-green-economy/ (Accessed 13 October 2020). 
Toronto Transit Commission (2017) Annual Report on Diversity and Human Rights Achievements [online]. Available at: http://www.toronto.ca/legdocs/mmis/2015/ex/bg rd/backgroundfile-85432.pdf (Accessed 13 October 2020).

Trichur, R. (2020) 'It's a 'She-Cession'. Governments Must Put Women First During the Recovery', Globe $\mathcal{E}$ Mail, May 1 [online]. Available at : https://www.theglobeandma il.com/business/commentary/article-legislators-must-prioritize-women-combat-work place-gender/ (Accessed 13 October 2020).

Turnbull, P. (2013) Promoting the Employment of Women in the Transport Sector: Obstacles and Policy Options [online]. Available at: https://www.ilo.org/sector/Res ources/publications/WCMS_234880/lang--en/index.htm (Accessed 13 October 2020).

UN Women (2012) 'Fast-forwarding Women's Leadership in the Green Economy', Women, June 19 [online]. Available at: https://www.unwomen.org/en/news/stories/2012/6/fast -forwarding-women-s-leadership-in-the-green-economy (Accessed 1 October 2020).

Women in Skilled Trades [WIST] (2017) [online]. Available at: https://www.westofwindsor .com/ (Accessed 13 October 2020).

Women's Budget Group (2020) What would a Feminist Green New Deal Look Like? [online]. Available at: https://wbg.org.uk/wp-content/uploads/2020/05/A-Feminist-Gr een-New-Deal.pdf (Accessed 13 October 2020). 